\title{
Penerapan Model Horton Untuk Kuantifikasi Laju Infiltrasi
}

\author{
Bismi Annisa ${ }^{1}$ \\ ${ }^{1}$ Departemen Teknik Sipil (Konsentrasi: Manajemen Sumber Daya Air dan Lingkungan), Universitas Islam \\ Riau, Jl. KH Nasution No. 113 Pekanbaru, email: bismi.annisa@eng.uir.ac.id
}

\begin{abstract}
Abstrak
Kapasitas infiltrasi akan semakin menurun bila bidang resapan air semakin berkurang. Dampaknya limpasan air hujan yang menjadi aliran permukaan akan semakin meningkat. Konsep perencanaan yang memperbesar air hujan meresap ke dalam tanah akan mampu mengurangi aliran permukaan. Penelitian ini bertujuan untuk kuantifikasi laju infiltrasi air hujan dengan menerapkan model Horton. Metode yang dilakukan adalah uji sampel di lapangan terhadap laju infiltrasi pada bidang tanah yang tidak ada lubang resapan dan bidang tanah yang diberi lubang resapan. Dimensi lubang resapan adalah diameter (Ø) 3 inchi, 4 inchi, dan 8 inchi dengan kedalaman 1,1 m menggunakan alat ukur double ring infiltrometer. Metode perhitungan menggunakan rumus infiltrasi Horton. Dapat disimpulkan bahwa lubang resapan berpengaruh terhadap peningkatkan laju infiltrasi air hujan ke dalam tanah, sehingga dapat meningkatkan daya resap air ke tanah. Laju infitrasi model Horton pada lubang resapan $\varnothing 3$ inchi, $\varnothing 4$ inchi, $\varnothing 8$ inchi dan tanpa lubang resapan adalah $\mathrm{f}(\mathrm{t})=0,55+0,45 \mathrm{e}^{-14 \mathrm{t}} ; \mathrm{f}(\mathrm{t})=$ $0,4+1,5 \mathrm{e}^{-19,5 \mathrm{t}} ; \mathrm{f}(\mathrm{t})=2,3+1,8 \mathrm{e}^{-46 \mathrm{t}} ;$ dan $\mathrm{f}(\mathrm{t})=0,28+0,72 \mathrm{e}^{-10,7 \mathrm{t}}$. Nilai laju infiltrasi yang paling besar hingga paling kecil adalah $\mathrm{f}(0)=4,1 \mathrm{~m} / \mathrm{jam}$ (pada $\varnothing 8 \mathrm{inchi}) ; \mathrm{f}(0)=1,9 \mathrm{~m} / \mathrm{jam}$ (pada $\varnothing 4 \mathrm{inchi}) ; \mathrm{f}(0)=1 \mathrm{~m} / \mathrm{jam}$ (pada $\varnothing 3 \mathrm{inchi}$ ); dan $\mathrm{f}(0)=1 \mathrm{~m} / \mathrm{jam}$ (tanpa lubang resapan). Perbandingan akumulasi waktu laju infiltrasi terhadap lubang resapan $\varnothing 8$ inchi adalah 3,8 kali lebih lambat (pada $\varnothing 3$ inchi), 3,6 kali lebih lambat (pada $\varnothing 4$ inchi), dan 6,63 kali lebih lambat (tanpa lubang resapan).
\end{abstract}

Kata kunci: laju infiltrasi, limpasan air hujan, model Horton 


\section{PENDAHULUAN}

Fenomena banjir disebabkan oleh beberapa faktor yang meliputi intensitas presipitasi, volume limpasan air hujan, rentang waktu presipitasi dan tingkat urbanisasi serta faktor-faktor lainnya $[1,8,12]$. Pembangunan gedung-gedung yang umumnya kurang memperhatikan ketersediaan ruang terbuka hijau berdampak terhadap semakin berkurangnya bidang resapan air. Pada saat terjadi presipitasi, sebagian air hujan masuk ke dalam tanah dan mengalami proses infiltrasi. Sedangkan sebagian lain ada yang tidak masuk ke dalam tanah, kemudian mengalir di atas permukaan tanah menuju elevasi yang lebih rendah. Genangan air sesaat terjadi karena keseimbangan air pada daerah tersebut terganggu. Kapasitas infiltrasi menjadi menurun sehingga menyebabkan meningkatnya limpasan air hujan yang menjadi aliran permukaan $[3,4]$. Dengan demikian dibutuhkan suatu perencanaan yang pada prinsipnya memperbesar air hujan meresap ke dalam tanah sehingga mengurangi aliran permukaan (run-off). Prinsip dasar konservasi air adalah meminimalisir air yang hilang sebagai aliran permukaan dan menyimpannya semaksimal mungkin ke dalam bumi. Berdasarkan prinsip ini maka curah hujan yang berlebihan pada musim hujan tidak dibiarkan mengalir ke laut tetapi ditampung dalam suatu wadah yang memungkinkan air kembali meresap ke dalam tanah (groundwater recharge) melalui pemanfaatan air hujan dengan cara membuat kolam pengumpul air hujan, sumur resapan dangkal, sumur resapan dalam dan Lubang Resapan Biopori [2,11]. Penelitian ini bertujuan untuk kuantifikasi laju infiltrasi air hujan dengan menerapkan model Horton.

\section{Infiltrasi}

Infiltrasi merupakan komponen utama dalam model limpasan air hujan yang mana model infiltrasi digunakan untuk prediksi limpasan air [7,9]. Infiltrasi merupakan air yang jatuh ke permukaan tanah dan meresap ke dalam tanah. Proses yang terjadi sebenarnya mencakup tiga proses berurutan, yaitu proses masuknya air ke permukaan tanah (infiltrasi), diikuti proses aliran air dalam tanah (water movement/water flow) dan perubahan tampungan dalam tanah (change of storage). Dengan demikian ketiga proses tersebut pada dasarnya tidak dapat dipisahkan satu dengan lainnya dan berpengaruh terhadap besaran laju infiltrasi $[1,3,4,5]$. Faktor-faktor yang mempengaruhi kapasitas infiltrasi $\left(f_{p}\right)$ adalah sebagai berikut.

a) Dalamnya genangan di atas permukaaan tanah (surface detention) dan tebal lapisan jenuh

b) Kadar air dalam tanah

c) Pemampatan oleh curah hujan

d) Tumbuh-tumbuhan

Kapasitas infiltrasi menurun selama waktu hujan sebagai akibat dari pemampatan permukaan tanah oleh pukulan butir-butir air hujan, mengembangnya tanah liat dan partikel-partikel humus oleh lembabnya tanah, tersumbatnya pori-pori oleh masuknya butir-butir tanah yang lebih kecil dan terperangkapnya udara dalam pori-pori tanah. Laju infiltrasi relatif terhadap debit air yang menentukan seberapa banyak air yang masuk ke zona an-saturasi dan seberapa banyak yang melimpas [13]. Pengembangan beberapa penyederhanaan model analitis infiltrasi dibutuhkan untuk memprediksi infiltrasi $[3,7,9,10,13]$. Selain itu juga dibutuhkan pengembangan metodemetode alternatif untuk meningkatkan kandungan organik tanah dan stabilitas struktur tanah untuk meningkatkan laju infiltrasi $[6,13]$.

\section{Model Horton}

Terdapat beberapa model infiltrasi, yakni model infiltrasi empiris (model Kostiakov, model Horton dan model Holtan) dan model berdasarkan fisik (Green \& Ampt dan Philip) [7]. Dari beberapa model infiltrasi, hanya sebagian yang berhasil diterapkan pada data lapangan. Kriteria penting dalam memilih model infiltrasi adalah berdasarkan kemudahan dalam menggunakannya untuk estimasi parameter- 
parameter pada model. Umumnya kesulitan tersebut adalah pada variabel karakteristik tanah [6]. Untuk memperoleh besaran infiltrasi, terdapat beberapa model empiris maupun teoritis. Berikut ini merupakan beberapa model empiris yang digunakan untuk memperoleh besaran infiltrasi $[3,7,9,10]$.

Horton mengamati bahwa laju infiltrasi dimulai dari fo dan berkurang secara eksponensial menjadi fc. Pada dasarnya model Horton ini hanya berlaku bila $i$ intensitas hujan $\geq f t$ laju infiltrasi sesaat [14]. Persamaan yang dihasilkan oleh model Horton adalah berdasarkan pendekatan hidrologi, yakni sebagai berikut.

$$
\begin{aligned}
& f(t)=f c+(f o-f c) e^{-k t} \\
& F(t)=f c \cdot t+\frac{(f o-f c)}{k}\left(1-e^{-k t}\right)
\end{aligned}
$$

Dimana: $\mathrm{F}=$ infiltrasi kumulatif $(\mathrm{m}$ atau $\mathrm{cm}) ; \mathrm{f}(\mathrm{t})=$ laju infiltrasi pada saat $\mathrm{t}(\mathrm{m} / \mathrm{jam}$ atau $\mathrm{m} / \mathrm{hari})$ atau kapasitas infiltrasi (fp); fo = laju infiltrasi awal ( $\mathrm{m} / \mathrm{jam}$ atau $\mathrm{m} / \mathrm{hari}) ; \mathrm{fc}=$ laju infiltrasi akhir setelah mencapai nilai tetap ( $\mathrm{m} / \mathrm{jam}$ atau $\mathrm{m} / \mathrm{hari}) ; \mathrm{k}=$ konstanta geofisik (/jam atau /hari); $\mathrm{t}=$ waktu sejak hujan turun (jam atau hari).

Infiltrasi kumulatif (F) di rumus (2), diperoleh dengan mengintegralkan luas di bawah kurva pada gambar 1 .

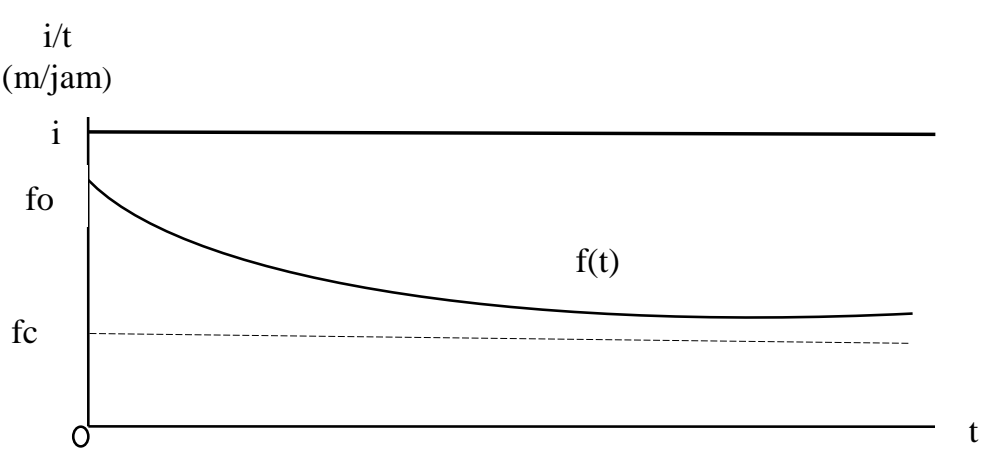

Gambar 1. $i$ Intensitas hujan $\geq \mathrm{f}(\mathrm{t})$ laju infiltrasi sesaat

\section{METODE PENELITIAN}

\section{Lokasi}

Lokasi pembuatan lubang resapan pada penelitian ini adalah di halaman Departemen Teknik Sipil FTUI Depok. Posisi lubang resapan, tepatnya di halaman antar selasar menuju gedung Engineering Centre dan Departemen Arsitektur.

\section{Peralatan dan bahan}

Peralatan dan bahan yang digunakan pada penelitian ini, adalah sebagai berikut.

- Alat tulis, kamera, ember, air, stop watch dan tabel data.

- Bor tanah (hand bor Auger Iwan) dan pipa (diameter $10 \mathrm{~cm} /$ disesuaikan dengan diameter lubang dan panjang minimal $10 \mathrm{~cm}$ ), atau adukan semen (lebar adukan 2-3 cm dan tebal $2 \mathrm{~cm}$ ) untuk perkuatan mulut lubang agar tidak runtuh.
- Double ring infiltrometer dengan diameter ring dalam $12 "(30,48 \mathrm{~cm})$, ring luar 24" $(60,96 \mathrm{~cm})$, tinggi alat 24" $(60,96 \mathrm{~cm})$, dan tebal plat ring $1 \mathrm{~mm}$ $(0,1 \mathrm{~cm})$.

- Godam (untuk memukul infiltrometer agar masuk ke dalam tanah) dan karet ban (untuk melindungi infiltrometer saat dipukul dengan godam agar infiltrometer tidak rusak akibat pukulan godam).

\section{Sampel dan Teknik Sampling}

Pada penelitian ini dilakukan uji sampel di lapangan terhadap laju infiltrasi pada bidang tanah yang diberi lubang resapan (tiga lubang resapan) dan bidang tanah yang tidak ada lubang resapan. Dimensi lubang resapan adalah diameter $(\varnothing) 3$ inchi $(0,0762$ $\mathrm{m}), 4$ inchi $(0,1016 \mathrm{~m}), 8$ inchi $(0,2032 \mathrm{~m})$, kedalaman 1,1 m dan jarak antar lubang 50 
cm. Untuk memperkuat pangkal lubang, digunakan pipa sesuai dengan diameter lubang dan panjang pipa minimal $15 \mathrm{~cm}$. Kemudian menutup lubang dengan pipa dop agar mereduksi masuknya benda asing dari arah vertikal (saat tidak dilakukan uji sampel).
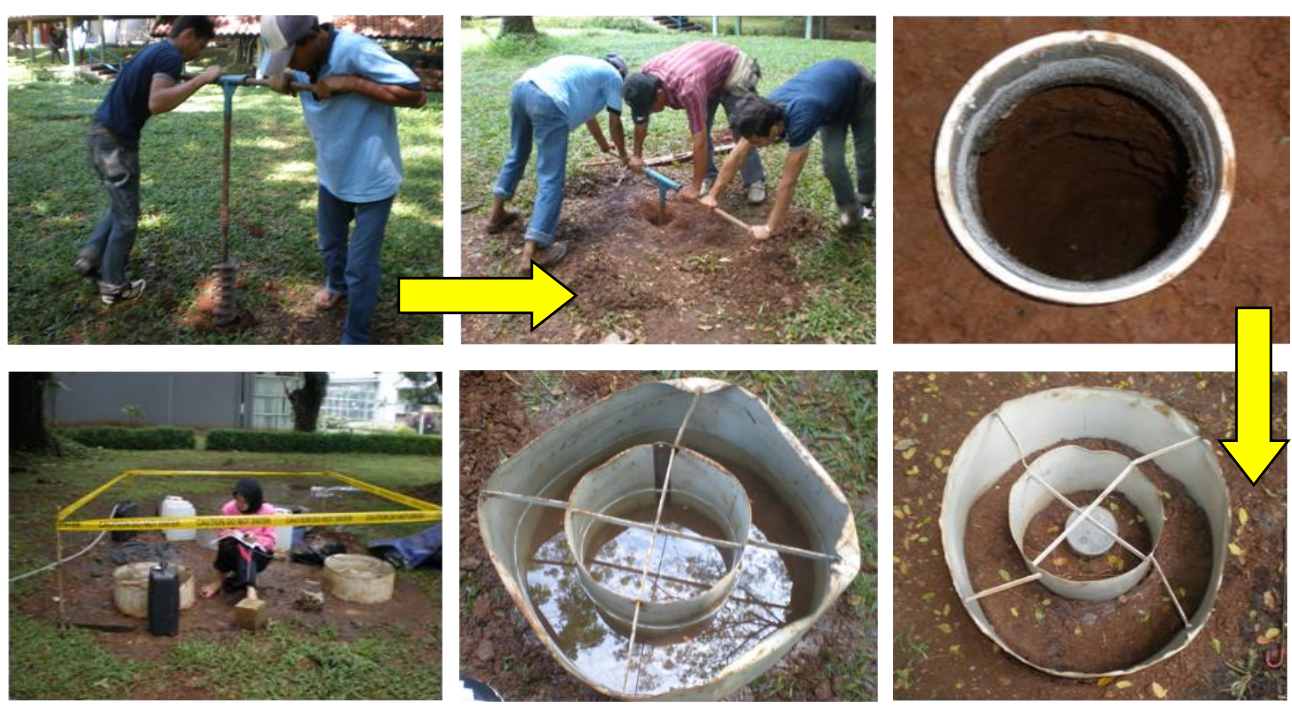

Gambar 2. Tahapan pengambilan data

Pengukuran infiltrasi pada lubang resapan, menggunakan double-ring infiltrometer. Data yang diambil dari pengukuran tersebut adalah penurunan muka air (h) terhadap akumulasi waktu (t). Infiltrometer ditaruh di atas lubang resapan yang telah dibuat, kemudian air dituangkan ke dalam infiltrometer tersebut. Ring luar (ring yang besar) dimasukkan secara konsentris ke dalam tanah dengan cara yang sama seperti ring dalam. Ruang antara ring luar dan ring dalam diisi air kemudian dibiarkan beberapa saat, akan terlihat air di sebelah dalam ring luar tersebut turun. Ruang tersebut diisi air kembali dan dilanjutkan dengan pengisian air di ring dalam. Air di bagian dalam ring luar selalu tetap tergenang hingga meresap habis ke dalam tanah. Pengukuran yang diperhatikan adalah pada ring dalam infiltrometer. Pengambilan data infiltrasi dilakukan sebanyak tiga kali pengulangan untuk setiap lubang resapan pada hari yang berbeda.

\section{Regresi dan Model Horton}

Persamaan yang menghubungkan dua atau lebih variabel dinamakan persamaan regresi. Analisa regresi digunakan sebagai alat untuk menguji hubungan sebab akibat antar variabel (gambar 3). Persamaan ini memberikan distribusi frekuensi dari satu variabel, apabila variabel lain ditetapkan dalam satu nilai tertentu, atau yang dapat digunakan untuk memperkirakan nilai suatu variabel bila nilai variabel lain diketahui. Derajat asosiasi sampel dari dua atau lebih variabel dinyatakan dalam koefisien korelasi.

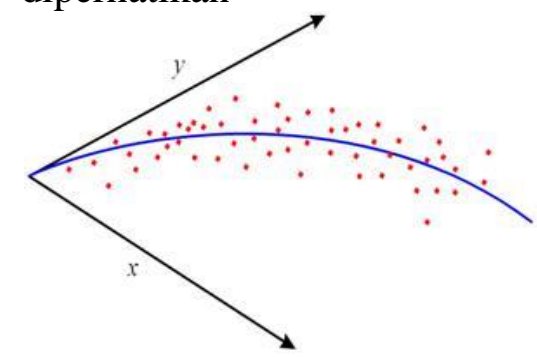

Gambar 3. Contoh kurva regresi 
Berdasarkan rumus (1) dan (2), terdapat beberapa parameter Horton yang harus ditemukan, yaitu fo (laju infiltrasi awal); fc (laju infiltrasi akhir setelah mencapai nilai tetap); k (konstanta geofisik); dan t (waktu sejak hujan turun). Pengamatan setiap turunnya air ke dalam tanah adalah setiap 5 detik. Parameter Horton tersebut dihitung dengan estimator least square di MS Excel.
Nilai fo, fc, dan $\mathrm{k}$ yang bervarisi ditebak dan dimasukkan ke dalam perhitungan estimator least square untuk memperoleh total square error (Eerror ${ }^{2}$ dari uji sampel pengulangan ke 1, 2 dan 3) terkecil yang dihasilkan dari variasi parameter tersebut. Parameter dengan Serror $^{2}$ terkecil yang dipilih untuk persamaan infiltrasi Horton (tabel 1).

Tabel 1. Estimator least square

\begin{tabular}{|c|c|c|c|c|c|}
\hline $\begin{array}{c}\mathbf{t} \\
(\mathbf{j a m})\end{array}$ & $\begin{array}{c}\mathbf{h} \\
(\mathbf{m})\end{array}$ & $\begin{array}{c}\text { F } \\
\text { Infiltrasi Kumulatif } \\
(\mathbf{m})\end{array}$ & $\begin{array}{c}\text { F Horton } \\
(\mathbf{m})\end{array}$ & Error $^{2}$ & $\begin{array}{c}\mathbf{f} \\
(\mathbf{m} / \mathbf{j a m})\end{array}$ \\
\hline & & & & & \\
\hline & & & & & \\
\hline
\end{tabular}

III. HASIL DAN PEMBAHASAN

Nilai parameter Horton yang menghasilkan Serror ${ }^{2}$ terkecil (hasil perhitungan dengan estimator least square), selanjutnya digunakan untuk model infiltrasi Horton (tabel 2). Hasil penelitian ini sesuai dengan rumus Horton yang menyatakan laju infiltrasi dimulai dari fo dan berkurang secara eksponensial menjadi fc. Sehingga grafik tergambar secara asimtot. Terbukti bahwa semakin besar bidang resapan tanah, maka air yang masuk dan meresap ke dalam tanah akan semakin besar pula pada awal peresapannya (fo). Uji sampel yang menggunakan lubang resapan membuktikan hubungan tersebut, yakni lubang resapan berdiameter lebih besar akan meresapkan air ke tanah lebih banyak dibanding yang berdiameter lebih kecil.
Rekapitulasi kuantifikasi laju infiltrasi model Horton dapat dilihat pada gambar 4 . Persamaan laju infitrasi pada lubang resapan $\varnothing 3$ inchi, $\varnothing 4$ inchi, $\varnothing 8$ inchi dan tanpa lubang resapan adalah $\mathrm{f}(\mathrm{t})=$ $0,55+0,45 \mathrm{e}^{-14 \mathrm{t}} ; \mathrm{f}(\mathrm{t})=0,4+1,5 \mathrm{e}^{-19,5 \mathrm{t}} ; \mathrm{f}(\mathrm{t})=$ $2,3+1,8 \mathrm{e}^{-46 \mathrm{t}} ;$ dan $\mathrm{f}(\mathrm{t})=0,28+0,72 \mathrm{e}^{-10,7 \mathrm{t}}$. Nilai laju infiltrasi yang paling besar hingga paling kecil adalah $\mathrm{f}(0)=4,1 \mathrm{~m} / \mathrm{jam}$ (pada $\varnothing 8$ inchi); f $(0)=1,9 \mathrm{~m} / \mathrm{jam}$ (pada $\varnothing 4$ inchi); $\mathrm{f}(0)=1 \mathrm{~m} / \mathrm{jam}$ (pada $\varnothing 3 \mathrm{inchi})$; dan $f(0)=1 \mathrm{~m} / \mathrm{jam}$ (tanpa lubang resapan). Perbandingan akumulasi waktu laju infiltrasi terhadap lubang resapan $\varnothing 8$ inchi adalah 3,8 kali lebih lambat (pada $\varnothing 3$ inchi), 3,6 kali lebih lambat (pada $\varnothing 4$ inchi), dan 6,63 kali lebih lambat (tanpa lubang resapan).

Tabel 2. Parameter Horton dan persamaan infiltrasi Horton

\begin{tabular}{|c|c|c|c|c|c|c|}
\hline \multirow{2}{*}{$\varnothing$} & \multirow{2}{*}{$\begin{array}{l}\text { Akumulasi } \\
\text { Waktu }\end{array}$} & \multicolumn{3}{|c|}{ Parameter Horton } & \multirow{2}{*}{$\Sigma e^{2 r r o r}{ }^{2}$} & \multirow{2}{*}{$\begin{array}{c}\text { Persamaan Infiltrasi Horton } \\
F(t) \text { dan } f(t)\end{array}$} \\
\hline & & fo & fc & $\mathbf{k}$ & & \\
\hline 3 & 19 & 1 & 0,55 & 14 & 0,0561664 & $\begin{array}{l}F(t)=0,55 t+0,03214\left(1-e^{-14 t}\right) \\
f(t)=0,55+0,45 e^{-14 t}\end{array}$ \\
\hline 4 & 18 & 1,9 & 0,4 & 19,5 & 0,3994343 & $\begin{array}{l}F(t)=0,4 t+0,07692\left(1-e^{-19,5 t}\right) \\
f(t)=0,4+1,5 e^{-19,5 t}\end{array}$ \\
\hline 8 & 5 & 4,1 & 2,3 & 46 & 0,1121856 & $\begin{array}{l}F(t)=2,3 t+0,03913\left(1-e^{-46 t}\right) \\
f(t)=2,3+1,8 e^{-46 t}\end{array}$ \\
\hline $\begin{array}{l}\text { Tanpa } \\
\text { Lubang }\end{array}$ & $\begin{array}{l}33 \text { menit } 15 \\
\text { detik }\end{array}$ & 1 & 0,28 & 10,7 & 0,0339721 & $\begin{array}{l}F(t)=0,28 t+0,06729\left(1-e^{-10,7 t}\right) \\
f(t)=0,28+0,72 e^{-10,7 t}\end{array}$ \\
\hline
\end{tabular}

Gambar 4 membuktikan bahwa keberadaan lubang resapan berpengaruh terhadap peningkatan laju infiltrasi air hujan ke dalam tanah. Secara rinci dapat dilihat pada gambar 5 mengenai infiltrasi kumulatif dan laju infiltrasi model Horton setiap uji 
sampel pengulangan ke 1, 2, dan 3. Terlihat bahwa bidang tanah yang tidak diberi lubang resapan menunjukkan akumulasi waktu yang paling lama bagi air hujan untuk meresap, sedangkan lubang resapan berdiameter 8 inchi menunjukkan akumulasi waktu yang paling singkat. Berdasarkan hasil penelitian, maka lubang resapan dengan kedalaman 1,1 m untuk diameter 8 inchi $(20,32 \mathrm{~cm})$ dan 4 inchi $(10,16 \mathrm{~cm})$ dapat direkomendasikan dalam bagian konservasi air.

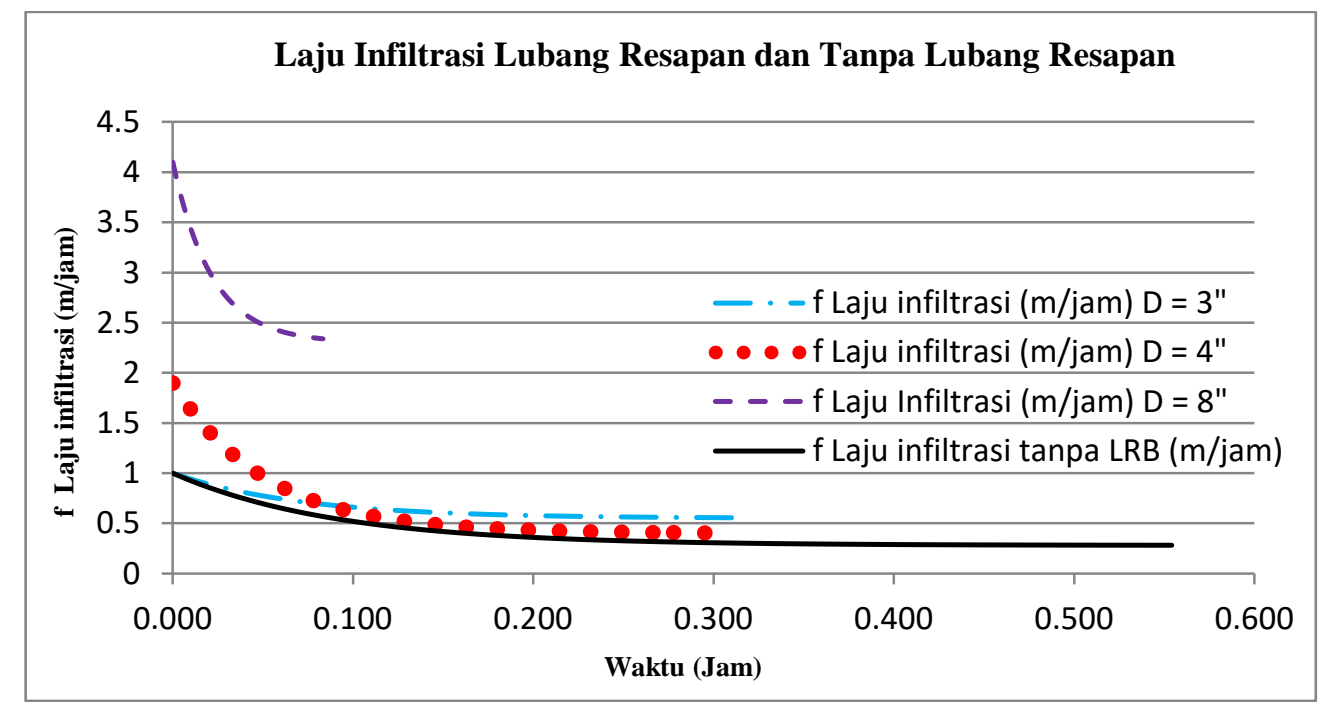

Gambar 4. Rekapitulasi Kuantifikasi Laju Infitrasi Model Horton

Secara prinsip, konservasi air bertujuan mencegah atau meminimalkan air yang hilang sebagai aliran permukaan dan menyimpannya sebanyak-banyaknya ke dalam bumi. Untuk menghasilkan laju infiltrasi yang cepat dan infiltrasi yang besar ke dalam tanah, harus diperhatikan ketepatan dimensi lubang resapan; jarak antar lubang resapan; dan formasi letak lubang resapan. Hal ini akan menjadi faktor penentu kejenuhan tanah. Jika sebelum turun hujan keadaan tanah masih sangat kering, maka di dalam tanah akan terjadi tarikan kapiler searah dengan gravitasi sehingga memberikan kapasitas infiltrasi (fp) yang lebih tinggi. Jika air mengalami perkolasi ke bawah, lapisan permukaan tanah akan menjadi setengah jenuh sehingga gaya-gaya kapiler mengecil dan fp menurun. Jika sebelum turun hujan, permukaan tanahnya sudah lembab, fp akan lebih rendah jika dibandingkan dengan permukaan tanah yang semula kering [14].

\section{KESIMPULAN}

Dapat disimpulkan bahwa lubang resapan berpengaruh terhadap peningkatan laju infiltrasi air hujan ke dalam tanah, sehingga dapat meningkatkan daya resap air ke tanah. Laju infitrasi model Horton pada lubang resapan $\varnothing 3$ inchi, $\varnothing 4$ inchi, $\varnothing 8$ inchi dan tanpa lubang resapan adalah $\mathrm{f}(\mathrm{t})$ $=0,55+0,45 \mathrm{e}^{-14 \mathrm{t}} ; \mathrm{f}(\mathrm{t})=0,4+1,5 \mathrm{e}^{-19,5 \mathrm{t}} ; \mathrm{f}(\mathrm{t})$ $=2,3+1,8 \mathrm{e}^{-46 \mathrm{t}} ;$ dan $\mathrm{f}(\mathrm{t})=0,28+0,72 \mathrm{e}^{-10,7 \mathrm{t}}$. Nilai laju infiltrasi yang paling besar hingga paling kecil adalah $\mathrm{f}(0)=4,1 \mathrm{~m} / \mathrm{jam}$ (pada $\varnothing 8$ inchi); f $(0)=1,9 \mathrm{~m} / \mathrm{jam}($ pada $\varnothing 4$ inchi); $\mathrm{f}(0)=1 \mathrm{~m} / \mathrm{jam}$ (pada $\varnothing 3$ inchi); dan $\mathrm{f}(0)=1 \mathrm{~m} / \mathrm{jam}$ (tanpa lubang resapan). Perbandingan akumulasi waktu laju infiltrasi terhadap lubang resapan $\varnothing 8$ inchi adalah 3,8 kali lebih lambat (pada $\varnothing 3$ inchi), 3,6 kali lebih lambat (pada $\varnothing 4$ inchi), dan 6,63 kali lebih lambat (tanpa lubang resapan). 
Penerapan Model Horton Untuk Kuantifikasi Laju Infiltrasi (Bismi Annisa)
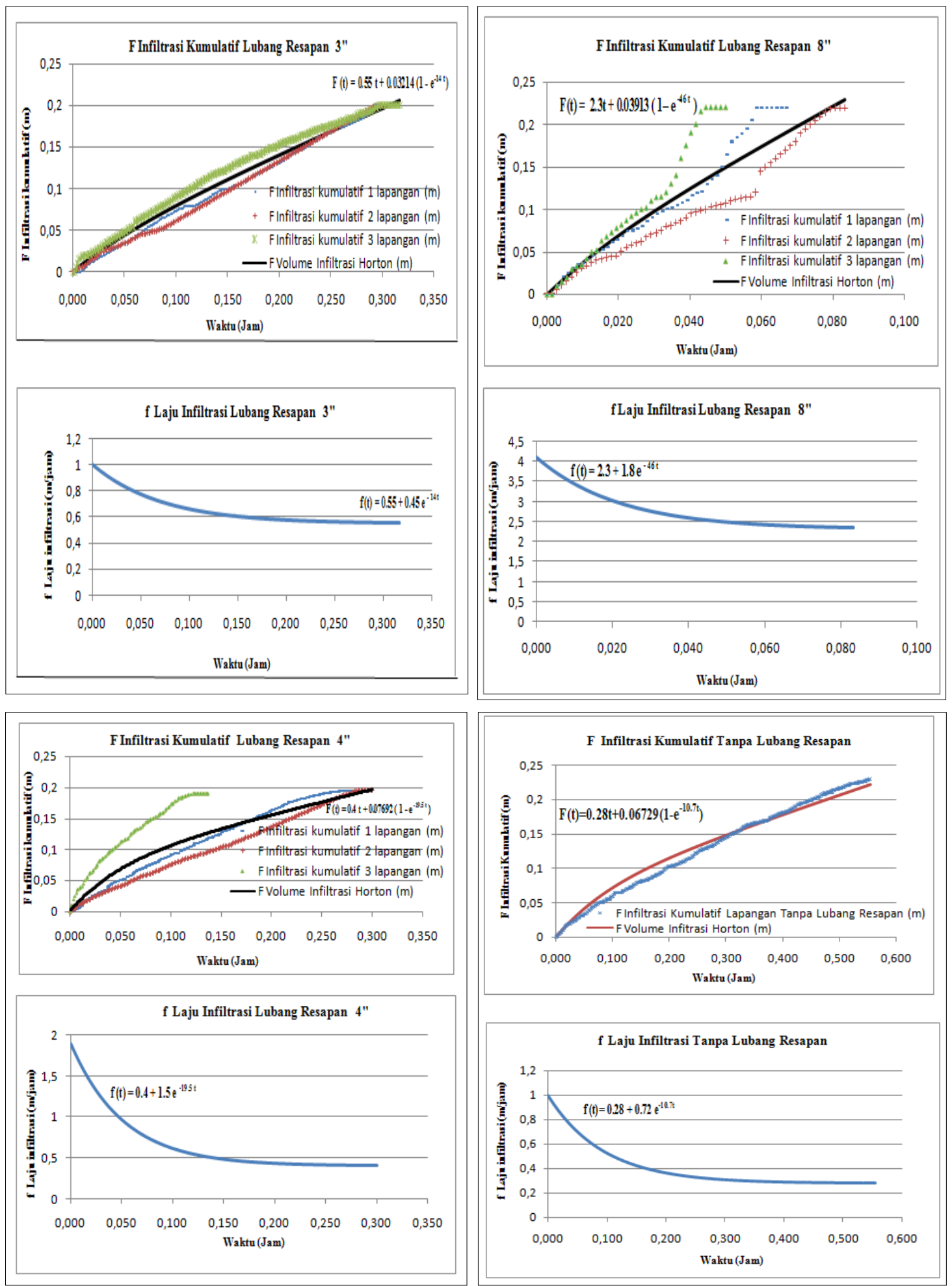

Gambar 5. Infiltrasi kumulatif dan laju infiltrasi model Horton (pengulangan ke 1,2 dan 3)

\section{DAFTAR PUSTAKA}

Bedient, B et al (1992) Hydrolgy and Floodplain Analysis, AddisonWesley Publishing Company, United States of America.
Brata, Kamir R (2009) Artikel Lubang Resapan Biopori, Bogor.

Chow,Ven Te et al (1998) Applied Hydrology, International Edtion, McGraw Hill Book Company, New York. 
Harto, Sri (1993) Analisis Hidrologi, PT Gramedia Pustaka Utama Anggota IKAPI, Jakarta.

Harto, Sri (2000) Hidrologi: Teori, Masalah, \& Penyelesaian, Nafiri Offset, Yogyakarta.

Hillel, D (1998) Environmental Soil Physics, Academic Press, San Diego, CA.

Jain, Ashu et al (2006), An evaluation of artificial neural network technique for the determination of infiltration model parameters, Applied Soft Computing, 6, 272-282

Kundzewicz, Z.W et al (2007) Freshwater resources and their management. Cambridge University Press, Cambridge, UK, pp. 173-210.

Machiwal, Deepesh et al (2006) Modelling Infiltration and quantifying Spatial Soil Variability in a Wasteland of Kharagpur, India, Journal of Biosystems Engineering-Soil and Water, 95(4), 569-582.
Marthanty, Dwinanti R (2008) Uji Kelayakan Metode Infiltrasi Horton Sebagai Alternatif Perhitungan Limpasan Hujan Metode SCS, Tesis, Departemen Teknik Sipil Universitas Indonesia, Depok.

Peraturan Menteri Negara Lingkungan Hidup Nomor 12 Tahun 2009 Tentang Pemanfaatan Air Hujan.

Petit-Boix, Anna et al (2015) Environmental and economic assessment of a pilot stormwater infiltration system for flood prevention in Brazil, Ecological Engineering, 84, 194-201.

Rao, K.P.C. et al (1998) Rainfall infltration and runoff from an Alfsol in semiarid tropical India. II. Tilled systems, Soil \& Tillage Research, 48, 61-69.

Soemarto, CD (1995) Hidrologi Teknik, Erlangga, Jakarta.

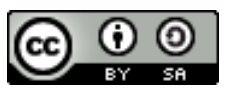

This is an open access article which means that all content is freely available without charge to the user or his/her institution. Jurnal Saintis allows the author(s) to hold the copyright without restriction. The copyright in the text of individual articles (including research articles, opinion articles, and abstracts) is the property of their respective authors distributed under the terms of the Creative Commons Attribution-ShareAlike 4.0 International License(https://creativecommons.org/licenses/by-sa/4.0/) which permits unrestricted use, distribution, and reproduction in any medium. Users are allowed to read, download, copy, distribute, search, or link to full-text articles in this journal without asking by giving appropriate credit, provide a link to the license, and indicate if changes were made. 